\title{
COMPARISON OF DENTAL STATUS AND ORAL FUNCTION BETWEEN THE ELDERLY WITH AND WITHOUT TEMPOROMANDIBULAR DISORDERS Minh Son Nguyen ${ }^{1,2 a^{*}}$, Ülle Voog-Oras $^{\text {1b }}$, Triin Jagomägi'c, Mare Saag ${ }^{\text {1d }}$
}

'Institute of Dentistry, Faculty of Medicine, University of Tartu, Raekoja plats 6, 51003 Tartu, Estonia

2Department of Prosthodontics, Faculty of Stomatology, Danang University of Medical Technology and Pharmacy, 99 Hung Vuong, Danang, Vietnam

\author{
aDDS, PhD, Head of Department \\ ${ }^{\mathrm{b} M D}$, PhD, Associate Professor \\ 'DDS, PhD, Associate Professor \\ dDDS, PhD, Professor, Head of Institute
}

\begin{abstract}
DOI: 10.25241/stomaeduj.2018.5(2).art.6

Introduction: Temporomandibular disorders (TMD) are a group of disorders that may cause functional limitations. The aim of the study was to compare the differences in dental status, oral behaviour, and mandibular functional limitations between TMD and non-TMD elderly people in Vietnam.

Methodology: The sample consisted of 146TMD and 112 non-TMD elderly. The dental and periodontal status were evaluated with DMFT and CPI indices. The participants self-rated frequency of oral behaviour activities (21-item Oral Behaviour Checklist) and mandibular functional limitations (20-item Jaw Functional Limitation Scale).

Results: The mean number of missing teeth in TMD group was $9.6 \pm 8.6$, while it was $7.6 \pm$ 6.4 in non-TMD group ( $p=0.036)$. Gingival bleeding in TMD group was detected at $18.3 \pm$ 10.2 teeth, which was less than in non-TMD group $(21.0 \pm 8.7, p=0.023)$. The mean number of sextants with a 0-3 mm clinical attachment loss was high for non-TMD group $(1.4 \pm 2.0$, $p=0.021)$, while the mean number of excluded sextants was high for TMD group $(1.3 \pm 1.8$, $p=0.037$ ). The TMD elderly group reported more frequent instances of "Hold, tighten, or tense muscles"than non-TMD group. No significant differences were found in the self-rated mandibular functional limitations between the two groups.

Conclusion: TMD were associated with missing teeth and periodontal diseases. There was no association between TMD and mandibular functional limitations. The elderly suffering from TMD tended to have increased frequency of holding, tightening, or tensing muscles. Keywords: dental caries, elderly, mastication, oral function, temporomandibular disorders.
\end{abstract}

OPEN ACCESS This is an
Open Access article under the CC
BY-NC 4.0 license.
Citation: Nguyen MS, Voog-Oras Ü,
Jagomägi I, Saag M. Comparison of dental
status and oral function in the elderly with
and without temporomandibular disor-
ders. Stoma Edu J. 2018:5(2):118-124.
Academic Editor: Hiroshi Ogawa, DDS,
MDSc, PhD, Associate Professor, Niigata
University, Niigata, Japan
Received: May 22, 2018
Revised: May 28, 2018
Acccepted: June 18, 2018
Published: June 20, 2018
*Corresponding author:Dr. Minh Son
Nguuyen, DDS, PhD Institute of Dentistry,
Faculty of Medicine, University of Tartu 6
Raekoja Plats, Tartu51003, Estonia. Tel:
+84983060321, Fax: +3727319856,e-mail:
minhson1883@ggmail.com
Copyright: $\odot 2018$ the Editorial Council
for the Stomatology Edu Journal.

\section{Introduction}

Temporomandibular disorders (TMD) are the group of disorders affecting the temporomandibular joint and structure-related joint. The prevalence of TMD in the older adult population varies from $33 \%$ to $56.6 \%[1,2]$ TMD often cause orofacial pain, limit the function of the masticatory system, and also impact on quality of life [3].

Multiple factors contribute to the TMD process. Dentition is a part of the masticatory system, and the global burden of dental caries and periodontal diseases can increase the risk of TMD in the older adult population [4]. Our previous studies indicate that more than $50 \%$ suffer from TMD [2]. Studies on TMD at the age over 60 years old also reported that $17.5-52.2 \%$ of patients had less than 20 teeth, and $10.9-34.3 \%$ were edentulousness [5-7]. After dental pain, TMD is the most the common cause of pain in the orofacial area; therefore, dental diseases and TMD may share symptoms and clinical comorbidities.

The parafunctional habits of bruxism and teeth clenching have been regarded as risk factors for TMD pain [8-10]. TMD patients are also limited in their daily activities and have increased frequency of oral parafunction [11,12]. The cumulative risk factors of ageing contribute to the increasing signs of TMD, including limited mouth opening, muscular tenderness, and TMJ sounds, all of which can affect on masticatory performance. Ohrbach et al. [13] and Markiewicz et al. [14] initially developed the Diagnostic Criteria for Temporomandibular Disorders (DC/TMD) axis II to determine the presence of parafunctional and functional limitations of the masticatory system. However, norms have not yet been established for those instruments, particularly in the older adult population. Regardless of whether or not elderly with TMD have more limited oral function compared to those free from TMD, because many factors such as dental status, neuromuscular changes, and psychosocial factors can influence oral function of this age group.

Therefore, the aim of the study was to compare the differences in dental status, oral behaviours, and functional limitations of the masticatory system between the TMD and non-TMD elderly people.

\section{Materials and methods}

The total sample comprised 258 volunteer participants aged 65-74 years in Danang City, Vietnam. Based on clinical examination of TMD according to DC/TMD axis 
I [15], our previous study revealed that $56.6 \%(n=146)$ of the total sample were diagnosed with TMD (TMD group) and $43.4 \%(n=112)$ were free of TMD (nonTMD group) [2]. In the current study, the participants of both groups were invited to examine dental status and evaluate oral function.

Written informed consent that explained oral examination procedures was obtained from each participant. This study was registered and approved by the Human Research Ethics Committee of the Danang University of Medical Technology and Pharmacy (No. 523/CN-DHKTYDDN 2014) and was performed in accordance with the World Medical Association's Helsinki Declaration.

\subsection{Clinical examination of dental status}

The dental status of each participant was examined by using the Decayed Missing Filled Teeth (DMFT) index. The primary caries appeared on the crown or root of a tooth, or secondary carious lesions nest to the restoration was considered a decayed tooth (DT). A missing tooth (MT) was a tooth lost due to caries or any other reason. A filled tooth (FT) was considered with at least one filled surface and without any caries. The DMFT score was the sum of the DT, MT, and FT scores and ranged from 0 to 32 .

\subsection{Clinical examination of periodontal status}

Periodontal status was evaluated using the modified Community Periodontal Index (CPI). The modified CPI records two indicators of periodontal status: gingival bleeding and periodontal pockets. All teeth present were probed ( 6 sites per tooth) to record any presence of bleeding on probing and periodontal pocket depth (PPD). PPD was scored as follows: score 0 (a PPD of 0-3mm, no pocket), score 1 (a PPD of 4-5mm, shallow pocket), and score 2 (a PPD of $\geq 6 \mathrm{~mm}$, deep pocket).

\subsection{Clinical examination of clinical attachment loss (CAL)}

CAL estimates accumulated lifetime destruction of the periodontal attachment. CAL was measured from the cementoenamel junction to gingival sulcus or pocket at 6 sites per index tooth of each sextant. The CAL severity was recorded based on the highest CAL score of the index tooth as follows: score 0 (CAL 0-3 mm), score 1 (CAL 4-5 mm), score 2 (CAL $\geq 6 \mathrm{~mm}$ ). The sextant was excluded if there were less than two teeth present.

The first author conducted procedure of dental and periodontal examination according to the WHO's Oral Health Survey guidelines (2013). A pilot study of a group of 25 elderly people was performed to calibrate the examiner before the study was carried out. Ten percent of the participants were re-examined after three days to test the reliability of the examination procedure. The calculated Kappa-values were above 0.85 , indicating a high degree of intra-examiner and inter-examination reliability.

\subsection{Evaluation of oral function}

All participants were interviewed face-to-face on the functional limitations of their masticatory system based on the 20-item Jaw Functional Limitation Scale
Table 1. Comparisons of dental caries status between the TMD and nonTMD elderly participants.

\begin{tabular}{rccc}
\hline Variable & $\begin{array}{c}\text { TMD } \\
(\mathbf{n}=\mathbf{1 4 6})\end{array}$ & $\begin{array}{c}\text { Non-TMD } \\
(\mathbf{n}=\mathbf{1 1 2})\end{array}$ & p-value \\
\hline Sound teeth & & & \\
\hline Number of subjects & 131 & 110 & \\
Percent \% & 89.7 & 98.2 & $0.009^{* a}$ \\
Mean number of teeth & $15.5 \pm 9.4$ & $17.6 \pm 8.7$ & 0.070 \\
\hline Decayed teeth & & & \\
\hline Number of subjects & 120 & 108 & \\
Percent \% & 82.2 & 96.4 & $<0.001^{* a}$ \\
Mean number of teeth & $6.3 \pm 5.6$ & $6.5 \pm 5.4$ & 0.684 \\
\hline Missing teeth & & & \\
\hline Number of subjects & 134 & 106 & \\
Percent \% & 91.8 & 94.6 & 0.463 \\
Mean number of teeth & $9.6 \pm 8.6$ & $7.6 \pm 6.4$ & $0.036^{* b}$ \\
\hline Filled teeth & \multicolumn{3}{c}{} \\
\hline Number of subjects & 12 & 10 & \\
Percent \% & 8.3 & 8.9 & 1.000 \\
Mean number of teeth & $0.2 \pm 0.9$ & $0.3 \pm 1.1$ & 0.710 \\
\hline Caries experience & & & \\
\hline Number of subjects & 143 & 111 & 0.635 \\
Percent \% & 97.9 & 99.1 & \\
\hline Mean DMFT & $16.0 \pm 9.5$ & $14.4 \pm 8.7$ & 0.152 \\
\hline & & & \\
\hline
\end{tabular}

a Fisher's exact test, ${ }^{\text {b }}$ Student t-test, ${ }^{*}$ statistically significant TMD: Temporomandibular disorders, DMFT: Decayed Missing Filled Teeth

(JFLS-20) [13] and the frequency of parafunctional behaviours based on the 21-item Oral Behaviour Checklist (OBC-21) [14].

JFLS-20 assesses the limitation of mastication ( 6 items), mandibular mobility (4 items), verbal and emotional expression communication items (8 items), swallowing, and yawning. Each item was scored on a scale of 0-10 points $(10$ points $=$ the most limited mandibular function).

OBC-21 determines the frequency of oral parafunctional activities during sleep and waking hours. Each item was scored from 0 (never) to 4 (all the time). In the current study, each item on the JFLS-20 and OBC-21 surveys was categorised as No (score $=0$ ) and Yes (score $\geq 1$ ).

The data was analysed using Version 17.0 of the Statistical Package for Social Sciences software (SPSS Inc., Chicago, III., USA). The comparisons of dental status, the frequency of parafunctional behaviours, and functional limitations of the masticatory system between the two groups was performed using Chisquare test and Student's t-test. A confidence level of $95 \%$ and a two-sided $p$-value of $<0.05$ were used to reveal significant differences.

\section{Results}

Prevalence of DMFT was $97.9 \%$ in the TMD group and $99.1 \%$ in the non-TMD group ( $p=0.635$ ). There were significant differences in prevalence between the TMD and the non-TMD groups in terms of sound 
Table 2. Comparisons of periodontal status between the TMD and nonTMD elderly.

\begin{tabular}{|c|c|c|c|}
\hline Variable & $\begin{array}{c}\text { TMD } \\
(n=146)\end{array}$ & $\begin{array}{c}\text { Non-TMD } \\
(\mathrm{n}=112)\end{array}$ & p-value \\
\hline \multicolumn{4}{|l|}{ Gingival bleeding } \\
\hline $\begin{array}{c}\text { Number of } \\
\text { participants (\%) }\end{array}$ & $135(92.5)$ & $110(98.2)$ & 0.467 \\
\hline $\begin{array}{c}\text { Mean number of } \\
\text { teeth }\end{array}$ & $18.3 \pm 10.2$ & $21.0 \pm 8.7$ & $0.023^{* c}$ \\
\hline \multicolumn{4}{|c|}{ Prevalence of participants having highest score of PPD } \\
\hline PPD 0-3 mm & $15(10.7)$ & $15(13.4)$ & 0.514 \\
\hline PPD 4-5 mm & $46(32.9)$ & $50(44.6)$ & 0.056 \\
\hline $\mathrm{PPD} \geq 6 \mathrm{~mm}$ & $78(55.7)$ & $47(42.0)$ & $0.030^{* a}$ \\
\hline \multicolumn{4}{|c|}{ Mean number of teeth present with PPD } \\
\hline PPD $0-3 \mathrm{~mm}$ & $12.3 \pm 10.2$ & $14.4 \pm 9.7$ & 0.085 \\
\hline PPD 4-5 mm & $7.3 \pm 7.9$ & $8.3 \pm 8.1$ & 0.342 \\
\hline $\mathrm{PPD} \geq 6 \mathrm{~mm}$ & $1.0 \pm 3.6$ & $0.6 \pm 1.7$ & 0.210 \\
\hline \multicolumn{4}{|c|}{ Prevalence of participants having highest score of CAL } \\
\hline CAL 0-3 mm & $2(1.4)$ & $12(10.7)$ & $0.001^{* \mathrm{~b}}$ \\
\hline CAL 4-5 mm & $38(26.0)$ & $42(37.5)$ & $0.048^{* a}$ \\
\hline $\mathrm{CAL} \geq 6 \mathrm{~mm}$ & $45(30.8)$ & $25(22.3)$ & 0.128 \\
\hline Excluded sextants & $61(41.8)$ & $33(29.5)$ & $0.042^{* a}$ \\
\hline \multicolumn{4}{|c|}{ Mean number of sextants with CAL and excluded sextants } \\
\hline CAL 0-3 mm & $0.9 \pm 1.4$ & $1.5 \pm 2.0$ & $0.021^{* c}$ \\
\hline CAL 4-5 mm & $2.4 \pm 2.0$ & $2.7 \pm 2.2$ & 0.184 \\
\hline $\mathrm{CAL} \geq 6 \mathrm{~mm}$ & $1.5 \pm 1.7$ & $1.0 \pm 1.7$ & 0.100 \\
\hline Excluded sextants & $1.2 \pm 1.8$ & $0.8 \pm 1.4$ & $0.037^{* \mathrm{c}}$ \\
\hline $\begin{array}{l}\text { a Chi-square test, b } \\
\text { statistically significant. } \\
\text { PPD: Periodontal pocke }\end{array}$ & $\begin{array}{l}\text { r's exact } \\
\text { pth; CAL: }\end{array}$ & , 'Stude & to-test, \\
\hline
\end{tabular}

teeth $(89.7 \%$ and $98.2 \%, \mathrm{p}=0.009)$ and decayed teeth $(82.2 \%$ and $96.4 \%, \mathrm{p}<0.001)$. The number of missing teeth was statistically higher in the TMD group $(9.6 \pm$ 8.6 teeth) than in the non-TMD group $(7.6 \pm 6.4, \mathrm{p}=$ 0.036 , Table 1).

Regarding periodontal status, gingival bleeding was detected at $18.3 \pm 10.2$ teeth in the TMD group, which was lower than $21.0 \pm 8.7$ teeth in the non-TMD group $(p=0.023)$. The prevalence of older adults with PPD $\geq 6 \mathrm{~mm}$ was higher in the TMD group (55.7\%) than in the non-TMD group ( $42 \%, p=0.030$ ). Concerning clinical attachment loss, occurrences of CAL 4-5 mm was $37.5 \%$ for the non-TMD group and $26.0 \%$ for the TMD group $(p=0.048)$; whereas, a high prevalence of excluded sextants was significantly related to the TMD group ( $41.8 \%, p=0.042)$. The mean number of sextants with CAL 0-3 mm was $0.9 \pm 1.4$ in the non-TMD group, which was statistically lower than $1.5 \pm 2.0$ sextants of the non-TMD group $(p=0.021)$; however, the TMD group had more excluded sextants $(1.3 \pm 1.8)$ than the non-TMD group $(0.7 \pm 1.4, p=0.037)$.

Comparing the functional limitations of mastication revealed no differences between the TMD and nonTMD group. Most participants in the TMD elderly group had masticatory limitations related to chewing tough food $(82.2 \%)$, followed by chewing chicken (69.2\%), and chewing hard bread (66.4\%); the results for the non-TMD group were $75.9 \%, 64.3 \%$, and $56.3 \%$, respectively. The mean score (standard error) of each
Table 3. Comparisons of functional limitations of masticatory system between the TMD and non-TMD elderly.

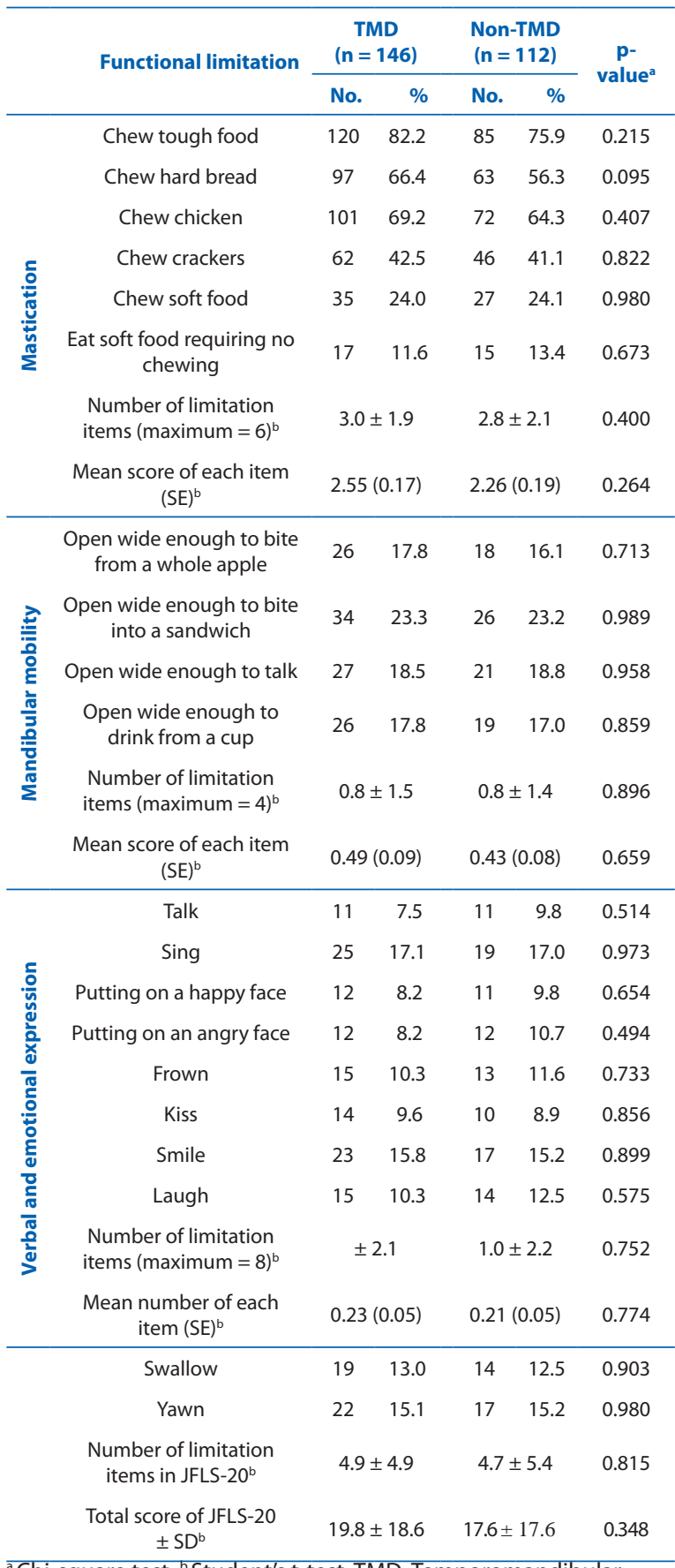

${ }^{a}$ Chi-square test, ${ }^{\mathrm{b}}$ Student's t-test. TMD: Temporomandibular disorders, SE: standard error, JFLS-20: 20-item Jaw Functional Limitation Scale.

of the masticatory items was $2.55(0.17)$ for the TMD group, compared to $2.26(0.19)$ for the non-TMD group $(p=0.260)$. The prevalence of limitations of mandibular mobility ranged from $17.8 \%$ to $23.3 \%$ in the TMD group, which were similar with the variation of $16.1 \%$ to $23.2 \%$ in the non-TMD group ( $p>0.05$ ). There were no significant differences between the two groups regarding limitations of verbal and emotional expression. The total score of JFLS-20 was $19.8 \pm 18.6$ in the TMD group and $17.6 \pm 17.6$ in the non-TMD group $(p=0.348$, Table 3$)$.

There were significant differences in the prevalence of parafunctional activities between the TMD and non-TMD groups in terms of "Hold, tighten, or tense 
muscles without clenching" $(7.5 \%$ and $1.8 \%, \mathrm{p}=$ $0.036)$ and "Eating between meals that food requires chewing" (43.2\% and 57.1\%, $p=0.026)$. The TMD group also tended to have more prevalent parafunctions of "Press tongue forcibly against teeth" and "Place tongue between teeth" ( $p=0.067$ and $p=0.079$, respectively) compared to the non-TMD group. No significant differences were found in the mean number of parafunctional items between the two groups ( $p=$ 0.928, Table 4).

\section{Discussion}

The current study highlighted a different dental status between the TMD elderly and non-TMD elderly groups. OurTMD elderly group lost an average of $9.6 \pm 8.6$ teeth and were higher than the non-TMD group; in other words, our study was in accordance with previous findings indicating that there was association of TMD with missing teeth [16-18]. When individuals lose many teeth, their chewing pattern can be changed and have impact on masticatory performance. Numerous studies indicated that chronic unilateral chewing increases the risk of TMD $[18,19]$. In addition, tooth loss causes social limitations, psychological disorders, and reduces the quality of life, all of which have been regarded as factors contributing to TMD.

The main finding of our study was that periodontal diseases have influence on TMD. PPD $\geq 4 \mathrm{~mm}$ indicates periodontal tissue destruction due to inflammation, while the CAL measurement estimates lifetime accumulated destruction of the periodontal attachment. These measures permit comparisons the severity of periodontal diseases between population groups. Our finding indicated that PPD and CAL were worse in the TMD group than in the non-TMD group. More than half of the TMD group had PPD $\geq 6 \mathrm{~mm}$ and over $70 \%$ of those had the CAL $\geq 6 \mathrm{~mm}$ and excluded sextants. All these numbers were comparatively high compared to $42 \%$ and $51.8 \%$, respectively, in the non-TMD group. In the elderly population, periodontal diseases are the most frequent cause of tooth loss; therefore, TMD was significantly associated with both periodontal diseases and tooth loss in the current study.

Gingival bleeding does not affect single tooth but can affect many remaining teeth in the mouth, but the TMD group had more missing teeth than the nonTMD. Therefore, the number of teeth with gingival bleeding was observed less in the TMD group in our study. Periodontal inflammation has been considered a potential risk factor for other diseases. Proinflammatory cytokines enhance the pathogenesis of periodontal diseases. Interleukin (IL-1) and tumour necrosis factor alpha (TNF-a) represent proinflammatory cytokines that stimulate a number of events which occur during infection with periodontal pathogens. Graves et al. found a widespread presence of IL-1 and TNF in the connective tissue and loss of alveolar bone along with periodontal inflammation [20]. High levels of IL-1 and TNF- $\alpha$ are a response to the inflammatory process and they might penetrate into the TMJ synovial fluid and cause bone tissue resorption; therefore, the degree of endogenous cytokine control is important for bone tissue destruction in the TMJ structure [21].
Table 4. Comparisons of parafunctional behaviours between the TMD and non-TMD elderly.

\begin{tabular}{lcccc}
\hline \multirow{3}{*}{ Parafunctional habit } & $\begin{array}{c}\text { TMD } \\
(n=146)\end{array}$ & $\begin{array}{c}\text { Non-TMD } \\
(n=112)\end{array}$ & $\begin{array}{c}p- \\
\text { value }^{a}\end{array}$ \\
\cline { 2 - 4 }$n$ & $n$ & $\%$ & $n$ &
\end{tabular}

Sleep activities

Clench or grind teeth when asleep

$\begin{array}{lllll}16 & 11.0 & 9 & 8.0 & 0.431\end{array}$

Sleep in a position that puts pressure on the jaw

$\begin{array}{lllll}57 & 39.0 & 44 & 39.3 & 0.968\end{array}$

Waking activities

Grind teeth together during waking hours

Clench teeth together during waking hours

Press, touch, or hold teeth together other than while eating

Hold, tighten, or tense muscles without clenching

Hold or put jaw forward or to the side

Press tongue forcibly against teeth

Place tongue between teeth

Bite, chew, or play with your tongue, cheeks or lips

Hold jaw in rigid or tense position

Hold between the teeth or bite objects

Use chewing gum

Play musical instrument that involves use of mouth or jaw Lean with your hand on the jaw

Chew food on one side only

Eating between meals that food requires chewing

Sustained talking

Singing

Yawning

Hold telephone between your head and shoulders

$9 \quad 6.2$

7

6.3

0.977

$\begin{array}{lllll}12 & 8.2 & 10 & 8.9 & 0.840\end{array}$

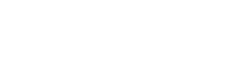

$\begin{array}{llll}19.2 & 24 & 21.4 & 0.655\end{array}$

$\begin{array}{lllll}11 & 7.5 & 2 & 1.8 & \mathbf{0 . 0 3 6}\end{array}$

$\begin{array}{lllll}17 & 11.6 & 11 & 9.8 & 0.64\end{array}$

$\begin{array}{lllll}31 & 21.2 & 14 & 12.5 & 0.067\end{array}$

$\begin{array}{lllll}32 & 21.9 & 15 & 13.4 & 0.079\end{array}$

$\begin{array}{lllll}27 & 18.5 & 19 & 17.0 & 0.750\end{array}$

$\begin{array}{lllll}17 & 11.6 & 10 & 8.9 & 0.480\end{array}$

$\begin{array}{llllll}8 & 5.5 & 8 & 7.1 & 0.583\end{array}$

$\begin{array}{lllll}20 & 13.7 & 19 & 17.0 & 0.468\end{array}$

$\begin{array}{lllll}4 & 2.7 & 1 & 0.9 & 0.392\end{array}$

$\begin{array}{lllll}50 & 34.2 & 36 & 32.1 & 0.722\end{array}$

$\begin{array}{lllll}82 & 56.2 & 63 & 56.3 & 0.989\end{array}$

$\begin{array}{lllll}63 & 43.2 & 64 & 57.1 & \mathbf{0 . 0 2 6}\end{array}$

$\begin{array}{lllll}67 & 45.9 & 49 & 43.8 & 0.732\end{array}$

$\begin{array}{lllll}33 & 22.6 & 34 & 30.4 & 0.159\end{array}$

$\begin{array}{lllll}48 & 32.9 & 43 & 38.4 & 0.353\end{array}$

Number of parafunctional habits

\begin{tabular}{cccccc}
\hline 0 & 15 & 10.3 & 12 & 10.7 & \\
$1-4$ & 72 & 49.3 & 54 & 48.2 & \\
$5-8$ & 36 & 24.7 & 31 & 27.7 & 0.921 \\
$\geq 9$ & 23 & 15.8 & 15 & 13.4 & \\
\hline
\end{tabular}

Mean number of $\quad 4.40 \pm 3.71 \quad 4.36 \pm 3.23 \quad 0.928$

$\begin{array}{llll}\text { parafunctional habits } \pm \text { SD }^{\mathrm{b}} & 4.40 \pm 3.71 & 4.36 \pm 3.23 & 0.928\end{array}$

a Chi-square test, ${ }^{b}$ Student's t-test, " statistically significant.

TMD: Temporomandibular disorders, SD: standard deviation.

Regarding peripheral sensitization, nociceptive afferents in the periodontal ligament could be activated when periodontal tissues under pressure become painful due to bacterial infections. Afferent nerve fibres carry the impulse to the trigeminal spinal tract nucleus and stimulate interneurons. The efferent fibres of the inhibitory interneurons synapse, which lead to the elevator muscle reaction, bring the teeth away from the noxious stimulus $[22,23]$. These repetitions might cause masticatory muscle dysfunction. The 
findings of Jeon et al. [19] suggested a positive correlation between chronic periodontitis and TMDrelated muscle pain, while Fabri et al. [24] found that there were clinical comorbidities between periodontal disease and craniofacial pains. All these studies support our findings indicating that periodontitis accumulated over time might be a risk factor for TMD.

TMD are a group of disorders that disrupt function or cause parafunction of the masticatory system. Surprisingly, the number of oral parafunctional activities was equal across two groups; participants in both groups had a range of 4-5 parafunctional behaviours. Our study is in accordance with Leketas et al.'s study [25] indicating that the behaviours of "Lean with your hand on the jaw", "Chew food on one side only", and "Sleep in a position that puts pressure on the jaw" were the most common in the TMD group. Meulen et al. [26] showed that these parafunctional behaviours often had higher scores than other parafunctional items when evaluating the validity items of OBC-21 in the Dutch population. This could suggest that the frequency of parafunctional behaviours affected TMD. The current study found that 2 out of 21 items of OBC were significantly associated with TMD among the elderly. The TMD group had higher frequency of "Hold, tighten, or tense muscles without clenching", but a lower frequency of "Eating between meals (i.e., food that requires chewing)" than the non-TMD group. These findings could be explained by muscular activity. The increasein the frequency of tensing muscles heightened the risk of TMD between 2.9-10.8 times [25]. Based on an electromyography study, Ohrbach et al. found [27] a high score of masseter muscular activity in subjects with tense muscles. A high activity of masseter muscle in combination with the neuromuscular change in older age would cause muscular disorders, a subgroup of TMD. This also explained why the TMD elderly group had a lower frequency of eating between meals in our study because of muscular impairment.

The current study reported difficulty chewing tough and hard food in most participants, but none indicating that TMD was related to functional limitations of mastication; such findings contrast with findings of Brandini et al. [28]. In older adults, the rate of loss was often higher in the posterior than the anterior teeth; therefore, the impaired masticatory performance was prevalent in both groups in our study. There were no differences between the two groups concerning other functional limitations related to mandibular mobility and verbal/emotional expression. However, limited mouth opening could occur with increasing age. Ikebe et al. found that $7.9 \%$ of elderly Japanese exhibited this limitation [29]. Similarly, our study demonstrated that approximately $23 \%$ of examinees self-reported a reduced mouth opening capacity to perform daily activities. The age-related degeneration of the temporomandibular joints and muscle weakness could contribute to such limitation in older people.

Although the prevalence of functional limitations was high in the TMD group, there were no correlations between the functional limitations of masticatory system and TMD when compared to the non-TMD group. This suggests that multiple factors could affect the function of the masticatory system in the elderly, including chronic orofacial pain, psychological disorders, and age-related reduction of the motor function of masticatory muscles [29-31]. The important finding of the current study was that determining the JFLS-20 score of older adults might enable us to predict $\mathrm{TMD}$, as the prevalence of TMD is correlated with an increasing JFLS-20 score in the general population [13]. The limitation of the study was that we only studied the oral function and parafunctional behaviours based on self-rated questionnaires. There is a need for more clinical research on this aspect.

\section{Conclusion}

Temporomandibular disorders were associated with missing teeth and periodontal diseases. There was no association between TMD and mandibular functional limitations among the elderly. The elderly suffering from TMD tended to have increased frequency of holding, tightening, or tensing muscles.

\section{Conflicts of interest}

The authors declare that they have no conflict of interest.

\section{Author contributions}

MSN searched literature, performed clinical studies, data acquisition and statistical analysis, and wrote draft of manuscript. ÜVO, TJ, and MS designed protocol, interpreted data, and edited the manuscript. All authors read and approved the final manuscript.

\section{Acknowledgements}

This study was supported by the Estonian Science Foundation grant ESF 9255, the Estonian Research Council IUT 20-46, and the Internationalization Programme DoRa of the European Social Fund, which is carried out by the Foundation Archimedes. The authors would like to thank the volunteer participants from the Hoa Vang, Hai Chau, Thanh Khe, and Cam Le districts of Danang City in Vietnam for their cooperation and agreement to provide data on their oral health and temporomandibular joint status.

\section{References}

1. Unell $L$, Johansson A, Ekbäck G, et al. Prevalence of troublesome symptoms related to temporomandibular disorders and awareness of bruxism in 65- and 75-year-old subjects. Gerodontology. 2012;29(2):e772-e779. doi:10.1111/j.17412358.2011.00558.x

[Full text links] [PubMed] Google Scholar(25) Scopus(9)

2. Nguyen MS, Jagomägi T, Nguyen T, et al. Symptoms and signs of temporomandibular disorders among elderly Vietnamese. Proc Singap Healthc. 2017;26(4):211-216. doi:10.1177/2010105817694907.

[Full text links] Google Scholar(1) Scopus(1)

3. Niibo P, Pruunsild C, Voog-Oras Ü, et al. Contemporary management of TMJ involvement in JIA patients and its orofacial consequences. EPMA J. 2016;7(1):1-9. doi:10.1186/ s13167-016-0061-7.

[Full text links] [Free PMC Article] [PubMed] Google Scholar(7) Scopus(2)

4. Kossioni EA. Recommended action plans for oral health in older Europeans. Stoma Edu J. 2018;5(1):6-7. doi: 10.25241/ stomaeduj.2018.5(1).edit.2.

[Full text links] Google Scholar() 
5. Sipilä K, Näpänkangas R, Könönen $M$, et al. The role of dental loss and denture status on clinical signs of temporomandibula disorders. J Oral Rehabil. 2013;40(1):15-23. doi:10.1111/j.13652842.2012.02345.x

[Full text links] [PubMed] Google Scholar(25) Scopus(15)

6. Katyayan PA, Katyayan MK, Patel GC. Association of edentulousness and removable prosthesis rehabilitation with severity of signs and symptoms of temporomandibular disorders. Indian J Dent Res. 2016;27(2):127-136. doi: 10.4103/0970-9290.183129.

[Full text links] [PubMed] Google Scholar(2) Scopus()

7. Nguyen MS, Voog-Oras Ü, Jagomägi T, et al. Tooth loss and risk factors among elderly Vietnamese. Stoma Edu J. 2016;3(34):178-183. doi: 10.25241/stomaeduj.2016.3(3-4).art.7. [Full text links] Google Scholar(1)

8. Manfredini D, Lobbezoo F. Relationship between bruxism and temporomandibular disorders: a systematic review of literature from 1998 to 2008. Oral Surg Oral Med Oral Pathol Oral Radiol Endod. 2010;109(6):e26-50. doi:10.1016/j.tripleo.2010.02.013. [Full text links] [PubMed] Google Scholar(255) Scopus(149)

9. Romaniuc D, Fala V, Lacusta V, et al. Manifestation of sleep bruxism according to the age of patients. Stomatol Edu J. 2018;5(1):31-37. doi: 10.25241/stomaeduj.2018.5(1).art.3. [Full text links]

10. Kino K, Sugisaki M, Haketa T, et al. The comparison between pains, difficulties in function, and associating factors of patients in subtypes of temporomandibular disorders. J Oral Rehabil. 2005;32(5):315-325. doi:10.1111/j.1365-2842.2004.01439.x. [Full text links] [PubMed] Google Scholar(88) Scopus(47)

11. Michelotti A, Cioffi I, Festa P, et al. Oral parafunctions as risk factors for diagnostic TMD subgroups. J Oral Rehabil. 2010;37(3):157-162. doi:10.1111/j.1365-2842.2009.02033.x. [Full text links] [PubMed] Google Scholar(146) Scopus(65)

12. Ohrbach $R$, Larsson $P$, List T. The jaw functional limitation scale: development, reliability, and validity of 8-item and 20-item versions. J Orofac Pain. 2008;22(3):219-230. [Full text links] [PubMed] Google Scholar(95) Scopus(57)

13. Markiewicz MR, Ohrbach R, McCall WD Jr. Oral behaviors checklist: reliability of performance in targeted waking-state behaviors. J Orofac Pain. 2006;20(4):306-316.

[Full text links] [PubMed] Google Scholar(47) Scopus(29)

14. Tallents RH, Macher DJ, Kyrkanides S, Katzberg RW, Moss ME. Prevalence of missing posterior teeth and intraarticular temporomandibular disorders. J Prosthet Dent. 2002;87(1):45 50. doi: $10.1067 / \mathrm{mpr} .2002 .121487$.

[Full text links] [PubMed] Google Scholar(144) Scopus(63)

15. Mundt T, Mack F, Schwahn C, et al. Association between sociodemographic, behavioral, and medical conditions and signs of temporomandibular disorders across gender: results of the study of health in Pomerania (SHIP-0). Int J Prosthodont. 2008;21(2):141-148.

[Full text links] [PubMed] Google Scholar(28) Scopus(14)

16. Nguyen MS, Jagomägi T, Nguyen T, et al. Occlusal support and temporomandibular disorders among elderly Vietnamese. Int J Prosthodont. 2017;30(5):465-470. doi:10.11607/ijp.5216. [Full text links] [PubMed] Google Scholar(0) Scopus(0)

17. Jeon $\mathrm{HM}$, Ahn YW, Jeong $\mathrm{SH}$, et al. Pattern analysis of patients with temporomandibular disorders resulting from unilateral mastication due to chronic periodontitis. J Periodontal Implant Sci. 2017:47(4):211-218. doi:10.5051/jpis.2017.47.4.211. [Full text links] [Free PMC Article] [PubMed] Google Scholar(0)
Scopus(0)

18. Graves D, Cochran D. The contribution of interleukin-1 and tumor necrosis factor to periodontal tissue destruction. J Periodontol. 2003;74(3):391-401. doi:10.1902/jop.2003.74.3.391. [Full text links] [PubMed] Google Scholar(824) Scopus(470)

19. Ahmed N, Petersson A, Catrina Al, et al. Tumor necrosis factor mediates temporomandibular joint bone tissue resorption in rheumatoid arthritis. Acta Odontol Scand. 2015;73(3):232-240. doi:10.3109/00016357.2014.994561.

[Full text links] [PubMed] Google Scholar(7) Scopus(5)

20. Wadachi R, Hargreaves KM. Trigeminal nociceptors express TLR4 and CD14: a mechanism for pain due to infection. J Dent Res. 2006;85(1):49-53. doi:10.1177/154405910608500108. [Full text links][Free PMC Article][PubMed]Google Scholar(208) Scopus(135)

21. Yin CS, Lee YJ, Lee YJ. Neurological influences of the temporomandibular joint. J Bodyw Mov Ther. 2007; 11 (4):285294. doi: 10.1016/j.jbmt.2006.11.007.

[Full text links] Google Scholar(26) Scopus(11)

22. Fabri GMC, Siqueira SRDT, Simione $C$, et al. Refractory craniofacial pain: is there a role of periodontal disease as a comorbidity? Arq Neuropsiquiatr. 2009;67(2B):474-479. doi:10.1590/S0004-282X2009000300018.

[Full text links] [PubMed] Google Scholar(13) Scopus(5)

23. Leketas M, Šaferis V, Kubilius R, et al. Oral Behaviors and parafunctions: comparison of temporomandibular dysfunction patients and controls. J Craniofac Surg. 2017;28(8):1933-1938. doi:10.1097/SCS.0000000000003945.

[Full text links] [PubMed] Google Scholar(0) Scopus(0)

24. van der Meulen MJ, Lobbezoo F, et al. Validity of the ora behaviours checklist: correlations between OBC scores and intensity of facial pain. J Oral Rehabil. 2014;41(2):115-121. doi:10.1111/joor.12114.

[Full text links] [PubMed] Google Scholar(15) Scopus(8)

25. Ohrbach R, Markiewicz MR, McCall JWD. Waking-state oral parafunctional behaviors: specificity and validity as assessed by electromyography. Eur J Oral Sci. 2008;116(5):438-444. doi:10.1111/j.1600-0722.2008.00560.x.

[Full text links] [PubMed] Google Scholar(48) Scopus(34)

26. Brandini DA, Benson J, Nicholas MK, et al. Chewing in temporomandibular disorder patients: an exploratory study of an association with some psychological variables. J Orofac Pain 2011;25(1):56-67.

[Full text links] [PubMed] Google Scholar(43) Scopus(25)

27. Ikebe K, Hazeyama T, Iwase $K$, et al. Association of symptomless TMJ sounds with occlusal force and masticatory performance in older adults. J Oral Rehabil. 2008;35(5):317-323. doi:10.1111/ j.1365-2842.2007.01841.x

[Full text links][PubMed]Google Scholar(17) Scopus(8)

28. Furuta M, Komiya-Nonaka M, Akifusa S, et al. Interrelationship of oral health status, swallowing function, nutritional status, and cognitive ability with activities of daily living in Japanese elderly people receiving home care services due to physical disabilities. Community Dent Oral Epidemiol. 2012;41(2):173181. doi:10.1111/cdoe.12000.

[Full text links] [PubMed] Google Scholar(88) Scopus(48)

29. Durham J, Touger-Decker R, Nixdorf DR, et al. Oro-facial pain and nutrition: a forgotten relationship? J Oral Rehabil. 2014:42(1):7580. doi:10.1111/joor.12226.

[Full text links] [PubMed] Google Scholar(3) Scopus(2)
Minh Son NGUYEN

Danang University of Medical Technology and Pharmacy 99 Hung Vuong, Danang, Vietnam

Dr. Minh Son Nguyen completed dental curriculum at the Hue University of Medicine and Pharmacy, Vietnam (2001-2007). He has been the lecturer of the Danang University of Medical Technology and Pharmacy Vietnam since 2008 and appointed as the Head of the Department of Prosthodontics in 2014. More than ten articles were published in international peer-reviewed journals, four manuscripts have been submitted for publication, and fourteen abstracts were presented at international conferences, all of which are his scientific achievements during the period of the Doctoral curriculum at the University of Tartu, Estonia (2014-2018). His research interest is related to prosthodontics, community dental health, geriatric dentistry, occlusion, orofacial pain, and temporomandibular disorders. 


\section{Questions}

\section{What is true for temporomandibular disorders (TMD)?}

口a. TMD mainly cause parafunctional behaviors;

b. The most prevalent orofacial pain is from TMD;

ac. It only affects temporomandibular joint;

$\square \mathrm{d}$. TMD signs tend to increase with aging.

\section{The Diagnostic Criteria for Temporomandibular Disorders (DC/TMD) axis II is} used to evaluate:

口a. Clinical signs of temporomandibular disorders:

b. Quality of life related to temporomandibular disorders;

c. Psychological domains and oral function;

$\square$ d. The balance of occlusion.

\section{Which is not considered as oral parafunction:}

a. Limited mouth opening;

b. Bruxism;

ac. Clenching;

$\square$ d. Unilateral chewing habit.

\section{Prevalence of edentulousness among TMD population is:}

ㅁa. $0-5 \%$.

b. $11-35 \%$;

ac. $51-70 \%$;

ad. Over $80 \%$.

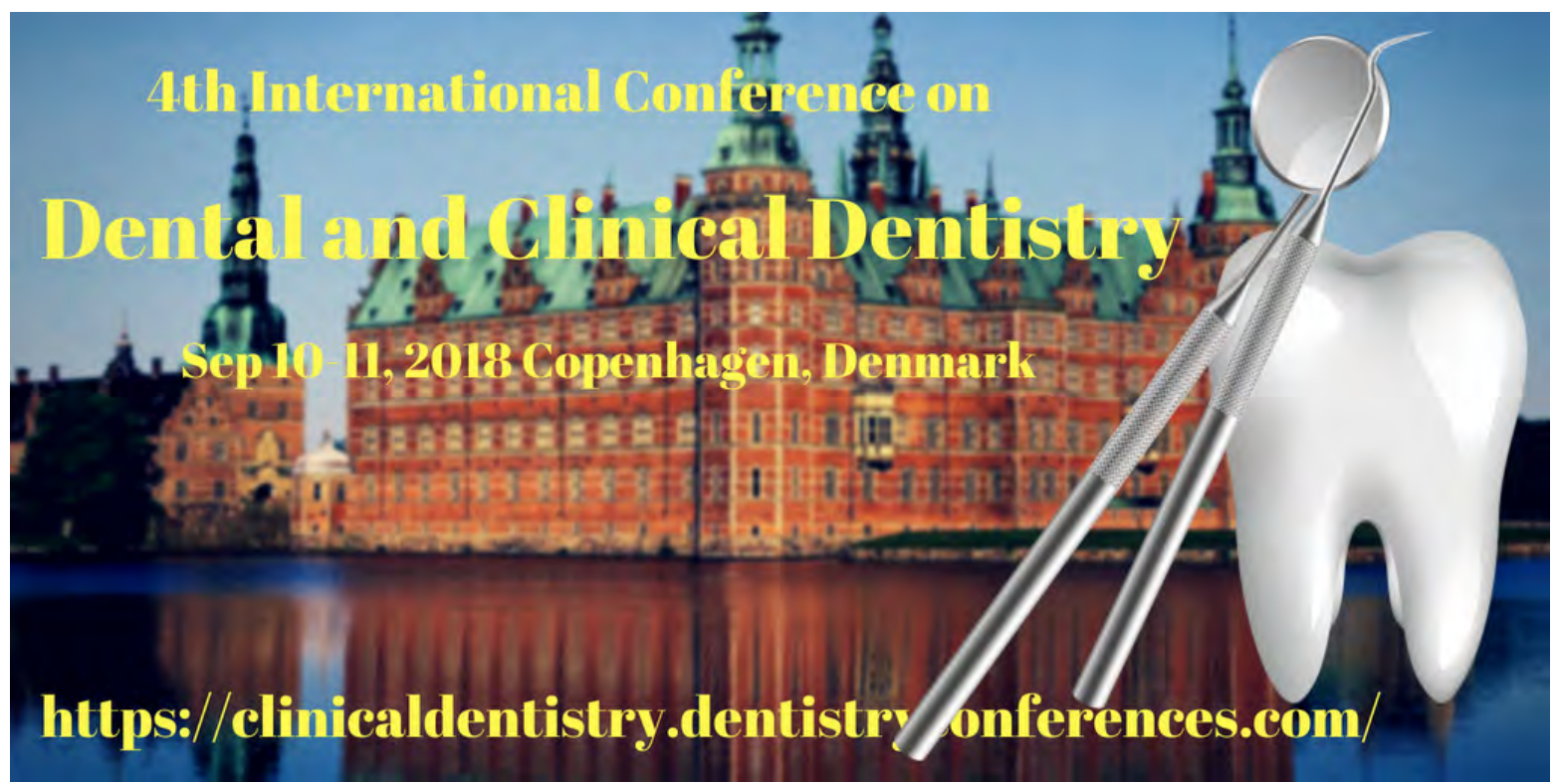

https://clinicaldentistry.dentistryconferences.com/ 